\title{
The influence of morphological and geographical traits on yield of Miscanthus sinensis during the first two years
}

\author{
Nuananong Purente ${ }^{1}$, Qiang Li ${ }^{1}$, Lanming Cui ${ }^{1}$, Jing Zhang ${ }^{2}$, Junhua Peng ${ }^{3}$, Miao He ${ }^{1}$ \\ ${ }^{1}$ Department of Landscape Architecture, Northeast Forestry University, 26 Hexing Road, Harbin, Heilongjiang 150040, China, ${ }^{2}$ Luohe Municipal \\ Engineering Design Institute, 162 Jiaotong Road, Yuanhui District, Luohe, Henan, 462099, China, ${ }^{3}$ China National Seed Group CO., LTD., A2 \\ Fuxingmenwai Street, Xicheng District, Beijing, 100045, China
}

\section{A B S T R A C T}

\begin{abstract}
Miscanthus is a $\mathrm{C}_{4}$ perennial energy crop distributed in various regions of China. Miscanthus sinensis has a high potential for biomass production, great adaptability to marginal land and tolerance to stress environmental. It's very important for the production and development of biofuel to review both the morphological and geographical traits on yield. However, the relevance of biomass yield and the geographical position of habitat are still not well known. In the present study, investigations of heading date, plant height, stem number and dry biomass per plant were carried out to calculate the influence of the morphological traits on yield. The investigation was based on 327 Miscanthus sinensis accessions collected from 21 provinces from all over China. The analysis was carried out on the basis of the two-year field experiment. The data for the second year was used to perform the analysis of variance and regression. Statistical data analysis was also performed on the variation of the biomass and morphological traits over successive period of study. The results showed that the growth included plant height and stem number in the following year was much better than the first year, particularly the biomass. Regression analysis revealed that latitude, plant height, and stem number were the key morphological traits that influence the biomass production. Also, heading date and elevation were found to be highly correlated to yield structure. These results demonstrated that the growth and yield were strongly influenced by geographical location, and apart from morphological traits, geographical traits were important factors that affect biomass.
\end{abstract}

Keywords: Biomass; Geographical traits; Heading date; Miscanthus sinensis; Morphological traits

\section{INTRODUCTION}

M. sinensis, one kind of Miscanthus, originated in the east of Asia and wildly distributed all over China. M. sinensis can grow beside river bank, agricultural land and even in the hilly areas from lower to the higher elevations (Chou, 2009). In the past decades, the reduction of non-regenerated energy and the increase in energy demand have attracted much interest in the research of an alternative energy. Besides, bioenergy study is the most prevalent topic and attracts wide attention. High-yield perennial grasses are considered as one of the most promising species for commercial bio-energy productions, due to low energy inputs and high outputs (Pyter et al., 2010). At present, production of biomass is significant breeding objective in bioenergy crops such as miscanthus (Heaton et al., 2010; Weijde et al., 2013). Field management practices like fertilization and harvest time can be very promising to improve the biomass quality
(Iqbal and Lewandowski, 2014; Lewandowski et al., 2003; Lewandowski and Heinz, 2003; Lewandowski and Kicherer, 1997). M. sinensis is a promising fiber yielding plants which having high potential in temperate climates for sustainable biomass production (Heaton et al., 2010). It is a perennial energy crop by high annual biomass production and high resource-use efficiency (Heaton et al., 2004; Heaton et al., 2008; Lewandowski et al., 2003; Long et al., 2001; Weijde et al., 2013). Miscanthus has a high yielding potential up to 40 tones $\mathrm{ha}^{-1} \mathrm{year}^{-1}$, with low input lignocellulosic feedstock. In biomass use yield for a plethora of applications, it shows growing interest, particularly for the production of bioenergy and biofuels (Brosses et al., 2012). Heaton et al. (2004) reported that switchgrass production approximately 12 tons ha ${ }^{-1}$ lower or half that of Miscanthus production observed in Europe. M. sinensis is high yield and, relative ease of husbandry using conventional equipment, therefore, it is a target species to renewable energy producers

\footnotetext{
${ }^{*}$ Corresponding author:

Nuananong Purente, Department of Landscape Architecture, Northeast Forestry University, 26 Hexing Road, Harbin, Heilongjiang 150040, China. Email: p.nuananong@hotmail.com
} 
(Atkinson, 2009). M. sinensis takes in atmospheric CO2 and assimilating it as plant tissue, and shares with its microbial partners in the soil (Clifton-Brown et al., 2007), or on the soil surface as leaf litter or other dead plant matter, which making it a plants carbon sequester (Heaton et al., 2009). Clifton-Brown et al. (2007) report a sequestration of 0.6 tones $C h a^{-1}$ year $^{-1}$. M. sinensis is also a crop with low nitrogen requirement showing a very impact on biomass production from fertilization (Himken et al., 1997). It also played a major role in reducing nitrogen from surface runoff (Heaton et al., 2008). Its broad range of variation of habitat indicates its adaptability on different kinds of extreme environment. It is one of the parents of Miscanthus $x$ giganteus having higher yields than switchgrass (Heaton et al., 2008) a perennial grass as received for its potential as a model bioenergy crop. $M$. sinensis stores approximately $30 \%$ of its total dry matter in root and rhizome (Bullard et al., 1995). According to Clifton-Brown et al. (2004), annual yields of $M$. sinensis across Europe depends on types of soil and climatic condition. Its production can range from 10 to 40 tones ha ${ }^{-1}$ year $^{-1}$. Clifton-Brown et al. (2001) indicated that an average yield of M. sinensis could reach 13.4 tones ha ${ }^{-1}$ year $^{-1}$. According to Clifton-Brown et al. (2001) and Lewandowski et al. (2003), the highest yields without irrigation were observed in autumn (17.9 tones $\mathrm{ha}^{-1}$ ) and winter (13 tones ha $\mathrm{a}^{-1}$ ) for M. sinensis hybrids and 14.3 and 8.9 tones ha ${ }^{-1}$ for M. sinensis (non-hybrid) in the autumn and winter harvests respectively. Work done by Jeżowski (2008) in Poland revealed that winter yields during the third year reached 20.5, 14.9 and 9.8 tones $\mathrm{ha}^{-1}$ for a hybrid between $M$. sinensis (2x) and M. sacchariflorus (4x), a hybrid between $M$. sinensis $(2 \mathrm{x})$ and $M$. sacchariflorus (2x) and a hybrid between two $M$. sinensis $(2 \mathrm{x})$ respectively. It is possible that M. sinensis can provide a genetic base for breeding because of the wide geographical distribution and genetic diversity and other characteristics. Several studies on traits, biomass yield, crop age, plant height, and tiller have been conducted worldwide (Huang et al., 2011; Jeżowski, 2008; Jeżowski et al., 2011; Zub et al., 2011). Although there have been numerous studies related in the literature, the relevance of biomass yield and the geographical position of habitat is still not well known. The aim of this study is to determine the variation of morphological and geographical traits during the first two years and find out the connections between the traits measured and dry biomass to confirm the key traits of biomass production.

\section{MATERIALS AND METHODS}

\section{Plant materials}

A total of 327 M. sinensis genotypes were collected from 21 provinces in China (Table 1). The geographical locations of these provinces ranged from $18^{\circ} 39.872 \mathrm{~N}-45^{\circ} 22.671 \mathrm{~N}$
Table 1: The information on collecting areas

\begin{tabular}{llc}
\hline Collection regions & Collection provinces & Sample number \\
\hline North of China & Hebei & 2 \\
North of China & Shanxi & 2 \\
Northeast of China & Liaoning & 1 \\
Northwest of China & Gansu & 10 \\
Northwest of China & Shaanxi & 21 \\
Central of China & Hubei & 43 \\
Central of China & Henan & 33 \\
Central of China & Hunan & 19 \\
East of China & Jiangsu & 7 \\
East of China & Shandong & 6 \\
East of China & Jiangxi & 21 \\
East of China & Anhui & 8 \\
East of China & Zhejiang & 12 \\
East of China & Fujian & 23 \\
Southwest of China & Yunnan & 17 \\
Southwest of China & Guizhou & 27 \\
Southwest of China & Sichuan & 20 \\
Southwest of China & Chongqing & 3 \\
South of China & Guangxi & 19 \\
South of China & Guangdong & 31 \\
South of China & Hainan & 3 \\
\hline
\end{tabular}

and $100^{\circ} 10.027 \mathrm{E}-127^{\circ} 34.816 \mathrm{E}$ covering north, northeast, south, southeast, southwest and central of China. All the resource samples were conserved in Wuhan Botanical Garden.

\section{Field trials}

The field experiments were conducted from 2015 to 2016 in a random designed plot of $23 \mathrm{~m} \times 28 \mathrm{~m}$, with proper irrigation and timely weed control in Wuhan Botanical Garden at Chinese Academy of Sciences. Fertilizer was not used during the observation period. The materials were planted during spring period in 2015 and harvested in winter of 2015 and 2016. Analysis of variance of yield structure traits was conducted on plant height (the distance from surface of the soil to the apex of spikelet), tillering (the number of shoots $20 \mathrm{~cm}$ above the ground per plant) and ripening time following the description by Jeżowski et al. (2011). Maturity was defined by the heading date. The data was defined the days between March 1st the date of planting and the beginning of flowering. Heading date (the days between March 1st and the beginning of heading) and flowering date (the days between March 1st and the date that more than $50 \%$ headed) were added to the survey data the second year. The yield was defined in the form of plant biomass. Measurements were taken after harvest of each year. Biomass (plant weight of dry yield) was determined by the average weight of each plant.

\section{Statistical analyses}

The data from planting until peak yield in the second year of cultivation were taken for analysis. In order to compare 


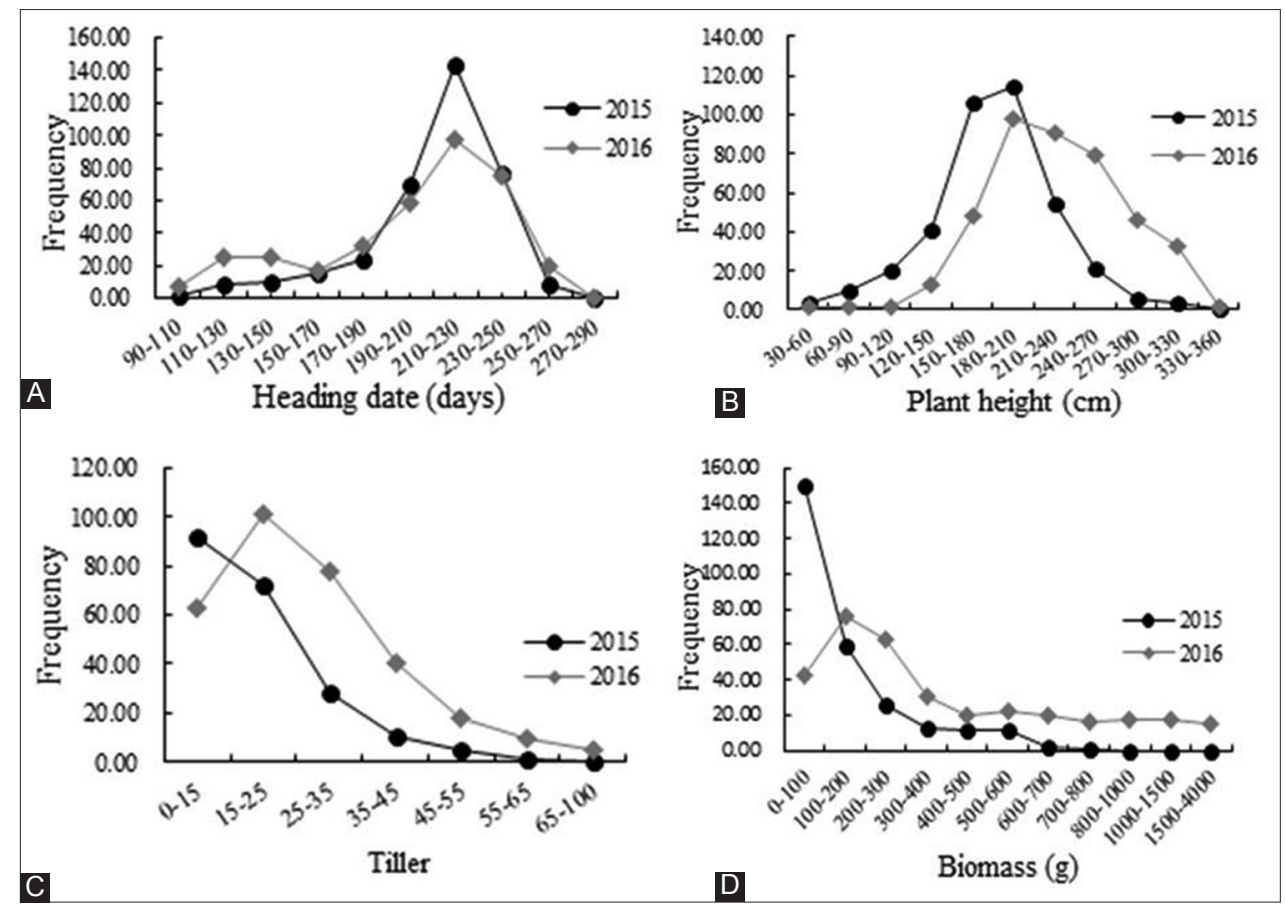

Fig 1. The distribution of frequency of heading date $(A)$, plant height $(B)$, tiller(C), biomass $(D)$ in the two years.

the samples from each years of the study, the results of the measurements were used to conduct a variance of analysis and two-factor analysis of variance. In the least significance difference (LSD) test was conducted at the 0.05 level of significance. Moreover, hypotheses of the geographical position of habitat were tested concerning the differences in the morphological traits obtained between the first and second years. The correlation between the traits affecting production and geographical factors were explored by excel. The correlations between the traits measured in this study were also analyzed. Multiple regression analysis were carried out using SPSS 13.0 (SPSS Inc., USA) to confirm the key traits that influence the biomass production (Soleymanifard et al., 2012).

\section{RESULTS}

\section{Agronomic traits}

The date on vegetative growth phase of $M$. sinensis collected started from June and lasted to November which is considered to be early winter in Wuhan. Most samples headed from about 150 days to 260 days after germination in the two years. Heading peak was observed on day 240 after germination (Fig. 1A). Samples collected from Liaoning, Shandong, Gansu, Shanxi, Henan and Hubei provinces headed earliest while samples from Guangdong, Hainan, Yunnan, and Fujian provinces entered the mating season at the latest. Fig. 1B presents the analysis of plant height, the result showed that plant height mainly concentrated in the range from 19 to $27.5 \mathrm{~cm}$. Most samples were more
Table 2: Traits comparison between the first and second year

\begin{tabular}{lcccc|}
\hline Contrast & Heading date & Plant height & Tiller & Biomass \\
\hline Y2-Y1 & $64.428^{* *}$ & $5.478^{*}$ & $8.321^{\star *}$ & $102.758^{\star *}$
\end{tabular}

Y1- The first year of the experiment

Y2- The second year of the experiment

*Significant at the 0.05 level, ${ }^{* *}$ Significant at the 0.01 level

than $15 \mathrm{~cm}$ and up to $33.5 \mathrm{~cm}$ maximum for the second year. Higher samples were from Sichuan (Southwest of china), Guangdong (South of China), Guangxi (South of China), and Fujian (East of China). Generally, samples were taller than the first year, with $35 \mathrm{~cm}$ equally, even up to $2 \mathrm{~m}$ partly. At the same time, the number of tillers per plant of each genotype showed a significant difference during the successive year of survey (Fig. 1C). The minimum of tillers per plant was only 10 , but the maximum was up to 95. The result proved the strong variation of tiller ability. Interestingly, tiller has the same situation as plant height that the genotypes with more tillers concentrated in the same province. The biomass ranged from 200 gram to more than 800 gram in the first year but increased many folds the next year (Fig. 1D). Outstanding performance on plant height, tiller and biomass were reported from the samples collected from Sichuan, Guangdong, Guangxi and Fujian provinces. The samples collected from Guangdong were even up to 4000 gram in the second year. In order to understand how the variations of traits affect biomass over successive years of cultivation, it is reasonable to analyze the differences in these traits between the two experimental years. Generally, heading date, plant height, tiller, and biomass all showed significant differences (Table 2). The decrease of heading 
date for the second year indicated that samples headed earlier in the second year probably due to the adaptive process to the environment change. But the same trend in the two years suggested that the length of the growth period was considered to be decided by genetic evolution year in year out. The plant height of the second year was significantly higher than the first year. The large increase in biomass in the second year was probably due to the augment of tiller and plant height (Figure 2).

\section{Correlation analysis of the morphological traits}

The correlation analysis was performed and the results are presented on Table 3. The results showed no correlation between plant height and heading date, full heading date, flowering date. Vegetative traits and plant height have a highly significant influence on leaf weight, stem weight, and biomass. The results of the main effect were positive. At the same time, it was noticed that there was a highly significant correlation between the heading date and the ratio of leaf and stem weight. The strong correlation between stem number and plant height suggested that higher altitude was accompanied by more vigorous tillers. Moreover, the ratio of leaf and stem weight showed significantly positive effect on biomass. It indicated that the heading date could affect the composition of biomass. The late heading will lead to a higher ratio, more leaves and less stem, and finally higher biomass further. The stable interaction between biomass and the ratio of leaf and stem weight suggested that the composition of biomass could affect yield. It could be inferred that heading date, plant height and stem number which are supposed to be the key factors affecting biomass.

\section{Correlation between morphological and geographical traits}

From the correlation analysis of geographical parameter and individual traits, heading date and ratio of leaf/stem were strongly negatively correlated with both longitude and latitude (Table4). Latitude had a strong negative influence on all individual traits. With exception of leaf/stem, all traits were negatively correlated with elevation. These results proved that the growth and yield were strongly influenced by geographical location. It inferred that populations at lower latitude and elevation would enter the reproductive stage later and had a longer vegetative

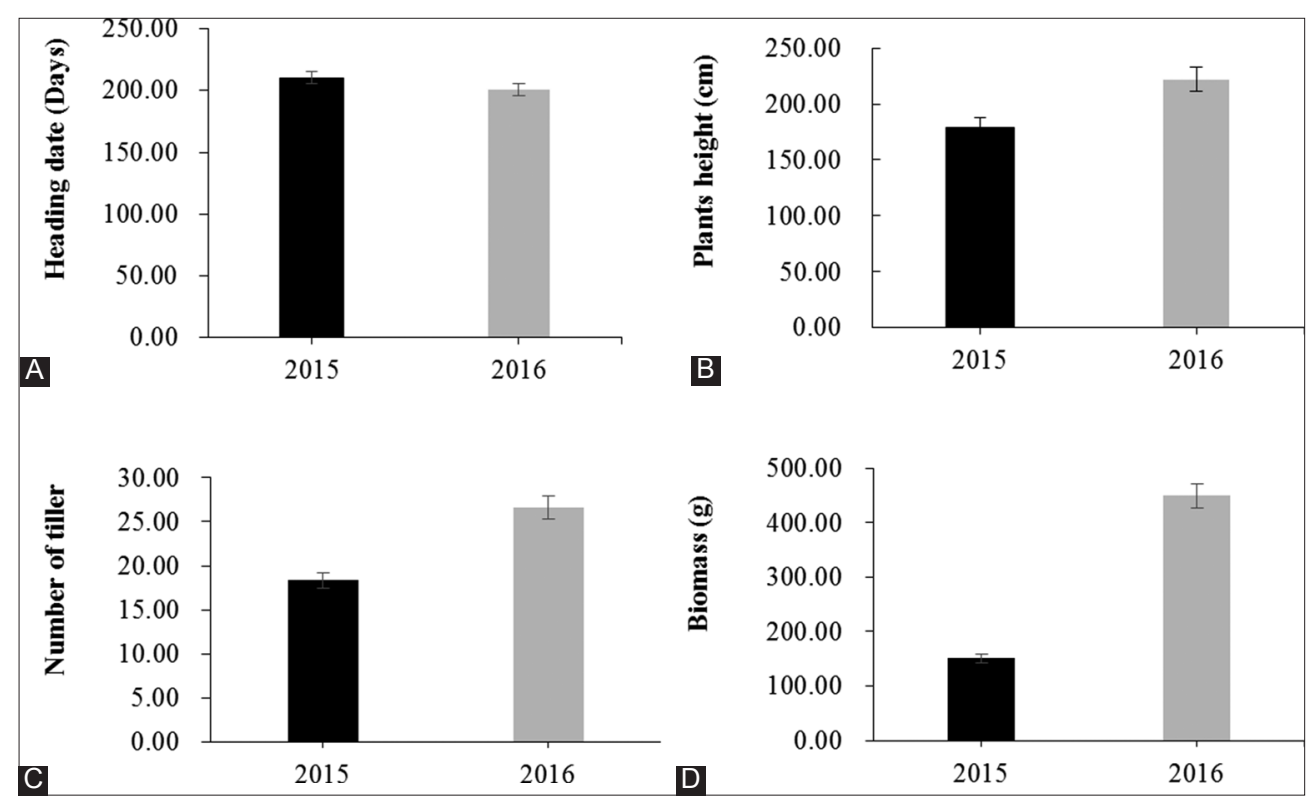

Fig 2. Bar graph showing (A) Heading date, (B) Plant height, (C) Tiller and (D) Biomass of successive year of survey.

Table 3: Correlation analysis of morphological traits and yield

\begin{tabular}{|c|c|c|c|c|c|c|c|c|}
\hline & $\begin{array}{l}\text { Heading } \\
\text { date }\end{array}$ & $\begin{array}{c}\text { Full heading } \\
\text { date }\end{array}$ & $\begin{array}{l}\text { Flowering } \\
\text { date }\end{array}$ & $\begin{array}{l}\text { Plant } \\
\text { height }\end{array}$ & $\begin{array}{c}\text { Stem } \\
\text { number }\end{array}$ & $\begin{array}{c}\text { Leaf } \\
\text { weight }\end{array}$ & $\begin{array}{c}\text { Stem } \\
\text { weight }\end{array}$ & $\begin{array}{l}\text { Ratio of } \\
\text { leaf/stem }\end{array}$ \\
\hline Full heading & $0.979^{\star \star}$ & & & & & & & \\
\hline Flowering date & $0.991^{\star *}$ & $0.975^{\star *}$ & & & & & & \\
\hline Plant height & 0.094 & 0.094 & 0.099 & & & & & \\
\hline Stem number & 0.103 & 0.106 & $0.122^{*}$ & $0.200^{* *}$ & & & & \\
\hline Leaf weight & $0.511^{* *}$ & $0.512^{* *}$ & $0.505^{\star *}$ & $0.480^{\star *}$ & $0.514^{\star *}$ & & & \\
\hline Stem weight & $0.382^{\star *}$ & $0.325^{\star *}$ & $0.323^{\star \star}$ & $0.628^{\star *}$ & $0.582^{\star *}$ & $0.841^{* *}$ & & \\
\hline Ratio of leaf/stem & $0.369^{\star \star}$ & $0.361^{\star *}$ & $0.353^{\star \star}$ & $-0.228^{* *}$ & -0.072 & $0.314^{* *}$ & $-0.198^{* *}$ & \\
\hline Biomass & $0.462^{* *}$ & $0.461^{\star *}$ & $0.456^{\star *}$ & $0.552^{\star \star}$ & $0.558^{* *}$ & $0.977^{* *}$ & $0.931^{* *}$ & $0.138^{*}$ \\
\hline
\end{tabular}

${ }^{*}$ Correlation is significant at the 0.05 level, ${ }^{* *}$ Correlation is significant at the 0.01 level 
Table 4: Correlation analysis of geographical and morphological traits

\begin{tabular}{lccc}
\hline & $\begin{array}{c}\text { North } \\
\text { latitude }\end{array}$ & $\begin{array}{c}\text { East } \\
\text { longitude }\end{array}$ & Elevation $(\mathrm{m})$ \\
\hline Heading date & $-0.898^{* *}$ & $-0.109^{*}$ & $-0.186^{* *}$ \\
Full heading & $-0.902^{* *}$ & -0.105 & $-0.165^{\star *}$ \\
Flowering date & $-0.904^{\star *}$ & -0.083 & $-0.192^{\star *}$ \\
Plant height & $-0.126^{*}$ & 0.033 & $-0.244^{\star *}$ \\
Stem number & $-0.124^{*}$ & -0.023 & -0.078 \\
Leaf weight & $-0.536^{* *}$ & -0.015 & $-0.251^{* *}$ \\
Stem weight & $-0.363^{* *}$ & 0.061 & $-0.309^{* *}$ \\
Ratio of leaf/stem & $-0.357^{* *}$ & $-0.188^{* *}$ & $0.127^{*}$ \\
Biomass & $-0.491^{* *}$ & 0.008 & $-0.276^{\star *}$ \\
\hline
\end{tabular}

${ }^{*}$ Correlation is significant at the 0.05 level, ${ }^{*}$ Correlation is significant at the 0.01 level

Table 5: Multivariate analysis of variance of morphological traits on biomass

\begin{tabular}{lcccc}
\hline Source of variation & DF & $\mathbf{R}^{2}$ & $\mathbf{F}$ & $\mathbf{P}$ \\
\hline Heading date & 109 & 0.413 & 1.330 & $0.041^{*}$ \\
Plant height & 124 & 0.542 & 1.783 & $0.000^{* *}$ \\
Stem number & 59 & 0.543 & 5.055 & $0.000^{* *}$ \\
Heading datexplant height & 75 & 0.993 & 1.745 & 0.249 \\
Heading datexstem number & 124 & 0.986 & 2.395 & $0.016^{*}$ \\
Plant heightxstem number & 121 & 0.993 & 1.159 & 0.475 \\
\hline R $^{2}$ coefficient of determination; DF: degree of freedom; F: F value; \\
P: probability; * significant at 0.05 ${ }^{* *}$, significant at 0.01
\end{tabular}

growth. Similarly, the plants with higher plant height and biomass most likely appeared in the lower latitude and elevation areas. The inference may due to the higher growth temperature in those areas. Moreover, we could get both materials propagated early in the high latitude and elevation areas and materials with great biomass in the low latitude and elevation areas. Both latitude and elevation were important factors of growth. The investigation conducted in the successive years of vegetation confirmed that the materials collected from southern China grew higher and lusher, but late heading. Differently, the materials from northern areas enter into the reproductive period earlier.

\section{Key traits for biomass production}

In order to understand the key traits that influence biomass production, further analysis of all production traits was conducted. The result of multivariate analysis of variance in table 5 demonstrates the strong impact of biomass which verified the inference that heading date, plant height and stem number supposed to be the key traits for biomass. There is no significant effect of the interaction between the heading date and plant height on the biomass. The interaction of plant height and stem number presented no apparent value of the main effect either. On the contrary, the interaction of heading date and stem number showed a significant effect of biomass.

Based on the analysis above, all traits measured that may affect the biomass were treated simultaneously in order to obtain the regression equation on biomass.
Regression equation was conducted with biomass $(\mathrm{Y})$ as the dependent variable and heading date $(\mathrm{X} 1)$, full heading date $\left(\mathrm{X}_{2}\right)$, flowering date $\left(\mathrm{X}_{3}\right)$, latitude $\left(\mathrm{X}_{4}\right)$, longitude $\left(\mathrm{X}_{5}\right)$, elevation $\left(\mathrm{X}_{6}\right)$, plant height $\left(\mathrm{X}_{7}\right)$ and stem number $\left(\mathrm{X}_{8}\right)$ as the independent variables. The correlation coefficient $\mathrm{R}$ was 0.743 , and the coefficient of determination $R^{2}$ was 0.553 . The analysis of variance showed $\mathrm{F}$ was $121.130, \mathrm{P}<0.01$ which meant the equation was effective. The equation $\mathrm{Y}=244.056-35.922 \mathrm{X}_{4}+3.521 \mathrm{X}_{7}+14.111 \mathrm{X}_{8}$ indicated that there was a linear relationship between biomass and latitude, plant height and stem number. When the plant height and stem numbers were fixed, biomass increased 279.978 as latitude reduced one degree. When the latitude and stem number were fixed, biomass increased 247.577 as plant height increased one unit. Similarly, when the latitude and stem number were fixed, biomass increased 258.167 as stem number increased by one.

\section{DISCUSSIONS}

The temperature difference for a year is very big between North and South of China, for the lowest temperature is $-22{ }^{\circ} \mathrm{C}$ and the highest temperature is $44{ }^{\circ} \mathrm{C}$. The influence of geographical from different temperature showed that the samples headed earlier mostly came from the north and northeast areas of China probably due to the low temperature and windy. On the contrary, the samples that came from the south of China headed at the latest likely because of perennial high temperature and sufficient sunlight. The North China area has short sunshine time and fast cooling, so the plants there reproduce earlier and are shorter hence the problem of plant breaking as a result of strong wind is mitigated. The environmental conditions in the southern parts of China make the plants have a long growth and enter into reproductive period very late. The samples which had better plant height, tiller and biomass were from Sichuan, Guangdong, Guangxi and Fujian provinces which indicated that the materials which came from these areas had the most potential. In addition, this situation suggested the correlation between plant height, tiller, and biomass. Important character especially biomass showed great changes between the first and second years of cultivation. The result showed that most samples grew better and provided a higher yield in the second year of cultivation. This is inconsistent with the findings of Clifton-Brown et al. (2001) and Jeżowski et al. (2011). The increase of plant height along with the increase of tiller may be the main reason for the significantly increase of biomass yield. Plant height increases the efficiency in the use of light. The ratio of leaf/stem had a significant positive effect on biomass, so it could be speculated that samples with more leaves could harvest more presumably due to the more leaves and the stronger photosynthesis. 
Considering the factors related to biomass, the crop age turns out to be one important factor. The biomass increase accompanied by the growth. Our results concur to that of Zub et al. (2011) and Jeżowski et al. (2011) that there is a significant augment between the two consecutive years of cultivation which indicated the connection between yield and crop age. Moreover, an increase in yield from the first year of cultivation to second was reported by Clifton-Brown et al. (2001). Lewandowski et al. (2003) further proved that peak yields can be attained in two years. Our results further revealed that plant height and tiller were key factors for biomass which agrees with the findings of Jeżowski (2008) and Huang et al. (2011). In their study, Jeżowski (2008) and Huang et al. (2011) noted that biomass of Miscanthus species had a significantly positive correlation to plant height and tiller number. According to Huang et al. (2011), elevation is an important variable that can influence the biomass of Miscanthus species. Our study reveals that apart from morphological traits, geographical traits were also important factors that affect biomass. This could be explained by the low temperature in high altitude area and also temperatures variations with latitude changes.

\section{CONCLUSION}

As one of the most potential energy crop, Miscanthus sinensis has attracted much attention worldwide. M. sinensis is widely distributed in China. The 327 samples collected from various parts of China basically representative populations of Chinese. There are lots of diversities of each individual trait. The wealth of resources provides a guarantee to develop new varieties. The observed morphological traits variation in the two years indicates that $M$. sinensis grow rapidly from the second year. Although the growth was very rapid within the two years, a question still remains about the year where the peak is reached. This, therefore, creates a gap for future research. In our study, we concluded that latitude, plant height, and stem number are the key factors that directly influenced the biomass. In addition, heading date and elevation also played key role in the resulting biomass.

\section{ACKNOWLEDGMENT}

The authors would like to acknowledge the financial support from the Fundamental Research Funds for the Central Universities (2572015EY03 and DL14C01).

\section{Authors' Contributions}

Nuananong Purente, Qiang Li, Jing Zhang; Designed and performed experiments, analysed data and co-wrote the paper. Junhua Peng; Performed transporter experiments. Lanming Cui; Co-analysed data. Miao He.; Supervised the research.

\section{REFERENCES}

Atkinson, C. J. 2009. Establishing perennial grass energy crops in the UK: A review of current propagation options for Miscanthus. Biomass Bioenergy. 33: 752-759.

Brosse, N., A. Dufour, X. Meng, Q. Sun and A. Ragauskas. 2012. Miscanthus: A fast-growing crop for biofuels and chemicals production. Biofuel. Bioprod. Biorefin. 6: 580-598.

Bullard, M. J., M. C. Heath and P. I. Nixon. 1995. Shoot growth, radiation interception and dry matter production and partitioning during the establishment phase of Miscanthus sinensis 'Giganteus' grown at two densities in the UK. Ann. Appl. Biol. 126: $365-378$.

Chou, C. H. 2009. Miscanthus plants used as an alternative biofuel material: The basic studies on ecology and molecular evolution. Renew. Energy. 34: 1908-1912.

Clifton-Brown, J. C., I. Lewandowski, B. Andersson, G. Basch, D. G. Christian, J. B. Kjeldsen and K. U. Schwarz. 2001. Performance of 15 miscanthus genotypes at five sites in Europe. Agron. J. 93: 1013-1019.

Clifton-Brown, J. C., J. Breuer and M. B. Jones. 2007. Carbon mitigation by the energy crop, miscanthus. Glob. Chang. Biol. 13: 2296-2307.

Clifton-Brown, J. C., P. F. Stampfl and M. B. Jones. 2004. Miscanthus biomass production for energy in Europe and its potential contribution to decreasing fossil fuel carbon emissions. Glob. Chang. Biol. 10: 509-518.

Heaton, E. A., T. Voigt and S. P. Long. 2004. A quantitative review comparing the yields of two candidate C4 perennial biomass crops in relation to nitrogen, temperature and water. Biomass Bioenergy. 27: 21-30.

Heaton, E. A., F. G. Dohleman and S. P. Long. 2008. Meeting US biofuel goals with less land: The potential of miscanthus. Glob. Chang. Biol. 14: 2000-2014.

Heaton, E. A., F. G. Dohleman and S. P. Long. 2009. Seasonal nitrogen dynamics of miscanthus $\mathrm{x}$ giganteus and Panicum virgatum. GCB Bioenergy. 1: 297-307.

Heaton, E. A., F. G. Dohleman, A. F. Miguez, J. A. Juvik, V. Lozovaya, J. Widholm and T. B. Voigt. 2010. Miscanthus: A promising biomass crop. Adv. Bot. Res. 56: 75-137.

Himken, M., J. Lammel, D. Neukirchen, U. Czypionka-Krause and H. W. Olfs. 1997. Cultivation of miscanthus under West European conditions: Seasonal changes in dry matter production, nutrient uptake and remobilization. Plant Soil. 189: 117-126.

Huang, C. L., W. C. Liao and Y. C. Lai. 2011. Cultivation studies of Taiwanese native Miscanthus floridulus lines. Biomass Bioenergy. 35: 1873-1877.

Iqbal, Y. and I. Lewandowski. 2014. Inter-annual variation in biomass combustion quality traits over five years in fifteen miscanthus genotypes in South Germany. Fuel Process. Technol. 121: 47-55.

Jeżowski, S. 2008. Yield traits of six clones of miscanthus in the first 3 years following planting in Poland. Ind. Crops Prod. 27: 65-68.

Jeżowski, S., K. Głowacka and Z. Kaczmarek. 2011. Variation on biomass yield and morphological traits of energy grasses from the genus miscanthus durig the first years of crop establishment Biomass Bioenergy. 35: 814-821.

Lewandowski, I., J. C. Clifton-Brown, B. Andesson, G. Basch, D. G. Christian, U. Jørgensen and K. Tayebi. 2003. Environment and harvest time affects the combustion qualities of miscanthus genotypes. Agron. J. 95: 1274-1280.

Lewandowski, I. and A. Heinz. 2003. Delayed harvest of miscanthusinfluences on biomass quantity and quality and environmental 
impacts of energy production. Eur. J. Agron. 19: 45-63.

Lewandowski, I. and A. Kicherer. 1997. Combustion quality of biomass: Ptatical relavance and experiments to modify the biomass quality of Miscanthus x giganteus. Eur. J. Agron. 6: 163-177.

Lewandowski, I., J. M. Scurlock, E. Lindvall and M. Christou. 2003. The development and current status of perennial rhizomatous grasses as energy crops in the US and Europe. Biomass Bioenergy. 25: 335-361.

Long, S. P., C. V. Beale and P. K. Farang. 2001. Resource capture by miscanthus. In: Miscanthus for Energy and Fiber, James and James Ltd., London, UK, p. 10-20.

Pyter, R. J., F. G. Dohleman and T. B. Voigt. 2010. Effects of rhizome size, depth of planting and cold storage on Miscanthus $\mathrm{x}$ giganteus establishment in the Midwestern USA. Biomass Bioenergy. 34: 1466-1470.

Soleymanifard, A., R. Naseri and M. Meysam. 2012. The study genetic variation and factor analysis for agronomic traits of Durum wheat genotypes using cluster analysis and path analysis under drought stress condition in western of Iran. Int. Res. J. Appl. Basic. Sci. 3: 479-485.

Weijde, T. V. D., C. L. A. Kamei, A. F. Torres, W. Vermerris, O. Dolstra, R. G. F. Visser and L. M. Trindade. 2013. The potential of C4 grasses for cellulosic biofuel production. Front. Plant Sci. 4: 107.

Zub, H. W., S. Arnoult and M. Brancourt-Hulmel. 2011. Key traits for biomass production identified in different Miscanthus species at two harvest dates. Biomass Bioenergy. 35: 637-651. 